\title{
STRENGTH, FRACTURE AND DEFORMATION BEHAVIOUR OF PORTLAND CEMENT PASTE
}

\section{Sagar Dwivedi* and P. L. Pratt}

Department of Metallurgy \& Materials Science, Imperial College of Science \& Technology, "Now at Steel Authority of India Lond, Research \& Developmert

\section{ABSTRACT}

The effect of strain rate on the strength and fracture toughness of cement paste has been studied at room temperature. At strain rates up to $10^{-3} / \mathrm{s}$ cement paste exhibits microductility, with rising strength and an activation volume of $1.5-2.0 \times 10^{4} \AA^{3}$. At strain rates above $10^{-3} / \mathrm{s}$ cement past behaves in a brittle manner with constant strength and a marked fall fracture toughness. This transition to brittleness is interpreted in terms of micro-shearing and slow crack growth. The critical strain rate

corresponds to the fastest relaxation process found in a stress-relaxation test.

\section{KEYWORDS}

Cement paste; strain rate; strength; fracture toughness; stress relaxation slow crack growth.

INTRODUCTION

The understanding of the strength and fracture behaviour of Portland cement paste is fundamental to the production of improved cementitious materials. paste is fundamental to the production of improved cencs to cement paste has In recent examined. A detailed study of the effect of external variables on the fracture toughness of cement paste has been carried out by Higgins and

Bailey (1976). An interesting conclusion drawn by these authors is that the stress-concentrating effect of notches in cement paste is small in comparison to metals, although Ziegeldorf, Müller and Hilsdorf (1981) have shown that it is large compared with mortar and concrete.

Many fracture mechanics studies on hardened cement paste may be criticised on the grounds that the notches were not sharp enough, or that corrections were not made for slow crack growth. Although a sharp crack may be produced by slow controlled loading (Hillemeier and Hilsdorf, 1977), the problem of accurate measurement of crack length remains. This difficulty is further 
compounded by the possibility of micro-cracking ahead of the main crack making it difficult to define the crack tip unambiguously. Hillemeier and Hilsdorf (1977) determined their fracture toughness values using compact tension specimens with sharpened cracks that were produced by slow stable crack growth. However, the advantage of using sharply cracked specimens may have been lost by using the compliance calibration curves determined from ordinarily notched specimens. They obtained a fracture toughness of $0.31 \mathrm{MPa} \mathrm{m}^{\frac{1}{2}}$ (Table 1) and this is close to the value obtained by other workers using the same water/cement ratio with sawn or cast notches.

In the present work we have investigated the effect of strain rate on the strength and fracture toughness of cement paste. An effort has been made to relate these results, in conjunction with relaxation and SEM studies, to the sub-microstructural features of hardened cement paste. Wittmann (1974) has shown that the creep mechanisms in cement paste are thermally activated and that the Arrhenlus rate equation applies. Our work extends this treatment rain rates.

\section{EXPERIMENTAL}

Specimens, in two different shapes $(12 \times 110 \times 220 \mathrm{~mm}$ plates and $40 \times 80 \mathrm{x}$ $320 \mathrm{~mm}$ beams), were prepared from ordinary Portland cement with a water/ cement ratio of 0.5 . After vibration, the mould and its contents were kept

(i) Plate specimens used for double torsion (DT) testing were grooved alon their length with a $1.0 \mathrm{~mm}$ thick diamond saw to a depth of $\sim 1 / 3$ of the thickness of the specimen. A notch was introduced at one end of the groove with the same saw except for two specimens which were notched with a groove saw. All DT specimens were 75-78 days old at the time of testing and were kept wet during grooving, notching or testing $\mathrm{K}$ was determined using the equation of Williams and Evans (1973).

$$
\mathrm{K}=\mathrm{Pw}_{\mathrm{m}}\left[\frac{3(1+\nu)}{\mathrm{wt^{3 }} \mathrm{t}_{\mathrm{n}}}\right]^{\frac{1}{2}}
$$

where $\mathrm{P}=$ total applied load, $\mathrm{w}_{\mathrm{m}}=$ length of each moment arm, $\mathrm{w}=$ plate width, $t=$ plate thickness,$t_{\mathrm{m}}=$ plate thickness in the plane $\nu=$ poisson's ratio.

(ii) Bend specimens cut from plates, 75-100 days old, were $12 \times 25 \times 100 \mathrm{~mm}$ (with a test span of $64 \mathrm{~mm}$ ) and those cut from beams, 35-40 days old, were, unless spak of 140 othe Nearly half thext, nom determined from the expression

$$
\sigma_{f}=3 / 2 \mathrm{PI} / \mathrm{bd}
$$

where $P$ is the load, 1 the beam span, $b$ the thickness, and $d$ the depth of the beam. Notches to act as crack-starters were cut into specimens used for single edge-notched bend (SENB) testing with diamond saws of $0.3 \mathrm{~mm}$ and testing, and the slits were introduced one day before testing. The stress
teriting intensity factor $\mathrm{K}$ for SENB tests is given by Brown and Srawley (1969) as

$$
K=\mathrm{x} \frac{3 \mathrm{PI} \mathrm{a}^{\frac{1}{2}}}{2 \mathrm{Bd} \mathrm{d}^{2}}
$$

where $\mathrm{Y}$ is a geometrical factor and $\mathrm{a}$ is the notch length.

(iii) Relaxation tests were conducted in three point bending on two, 40 day old, unnotched beams $(40 \times 40 \times 160 \mathrm{~mm})$ cut from a large beam. Each

specimen was loaded to a predetermined load $\mathrm{P}$ and, after a desired period of load relaxation, a repeat relaxation test was carried out by reloading the specimen to $P$ and allowing it to relax again. For thermally activated processes the relaxation test results can be represented (Klug and

Wittmann, 1974) by

$$
\Delta \sigma \equiv \sigma_{0}-\sigma=\frac{\mathrm{kT}}{\mathrm{V}} \ln (1+\mathrm{At})
$$

where $\sigma o$ and $\sigma$ are stresses at times zero and ' $t$ ' respectively, $k$ is the Boltzman constant, $\mathrm{T}$ is the absolute temperature, $\mathrm{A}$ is a constant, and $\mathrm{V}$ is the

$$
\Delta \sigma=\frac{k T}{V}(\ln A+\ln t)
$$

which can be used to determine the activation volume. In the determination of activation volume from equation 5 and equation 6 we have used the maximu tensile flexural stresses, $\sigma$, rather than the more usual shear stress $\tau$.

\section{RESULTS}

In agreement with Nadeau, Mindess and Hay (1974) the values of $K_{\mathrm{TC}}$ obtained from DT and from SENB tests in this work were found to be very similar at cross-head from SENB tests in this

\section{TABLE 1 Fracture Toughness of Hardened Cement Paste}

\begin{tabular}{clllc}
\hline Reference & Method & w/c & Age (days) & K IC MPa $\mathrm{m}^{\frac{1}{2}}$ \\
\hline This work & 3-BD & 0.5 & $75-100$ & 0.34 \\
This work & DT & 0.5 & $75-100$ & $0.30-0.36$ \\
1 & $3-$ BD & 0.5 & $78-99$ & 0.32 \\
1 & DT & 0.5 & $78-99$ & $0.29-0.34$ \\
2 & $4-B D$ & 0.47 & $14-84$ & 0.33 \\
3 & CT & 0.4 & $>50$ & 0.31 \\
4 & 3-BD & 0.5 & $75-100$ & 0.30 \\
4 & 3-BD & 0.3 & $75-100$ & 0.40 \\
5 & $4-B D$ & 0.3 & 41 & $0.49-0.66$ \\
\hline
\end{tabular}

$1=$ Nadeau, Mindess and Hay $; 2=$ Brown and Pomeroy; $3=$ Hillemeier and
Hilsdorf $; 4=$ Higgins and Bailey; $5=$ Mindess, Lawrence and Kesler. 
The high values for DT were calculated from the maximum load and the low ones from the load at instability. The results from the DT tests wer independent of the length and thickness of the notch, whereas for SENB tests $\mathrm{K}_{\mathrm{IC}}$ increased with notch thickness from $0.3 \mathrm{~mm}$ to $1.0 \mathrm{~mm}$ but was independen are for length in the range a/d $=0.2-0.5$. All sENB results reported below within the range af hotch thickness $0.3 \mathrm{~mm}$. The latter value lies well the stress intensity factor was independent of notch thickness. The high values of $\mathrm{K}_{\mathrm{H}}$ of Mindess, Lawrence and Kesler (1977) (Table 1), appear to be due mainly to the large thickness $(3 \mathrm{~mm}$ ) of their notch since $\mathrm{Higgins}$ to be Bailey (1976) also found $K_{T C} \cong 0.6$ at $\mathrm{w} / \mathrm{c}=0.3 \mathrm{with}$ a notch $3 \mathrm{~mm}$ thick. The width of the damage zone ahead of the crack tip in cement paste appears to be $\sim 0.4 \mathrm{~mm}$ and any notch thicker than this cannot be treated as appears crack. If we treat the notch as an elliptical crack, with $3 \mathrm{~mm}$ as the radius at the apex, then for $\mathrm{K}$ values of $0.49-0.66 \mathrm{MPa} \mathrm{m}^{\frac{1}{2}}$ (Mindess, Lawrence and Kesler, 1977) and a crack length of $440-50 \mathrm{~mm}$, we obtain fracture strengths for unnotched beams equal to $11-15 \mathrm{MPa}$. These are in good agreement with the experimental strength of beams with $\mathrm{w} / \mathrm{c}=0.3$, measured by Higgins and Bailey (1976). The Table shows that, for sharp notches, there is an increase in $\mathrm{K}_{\mathrm{IC}}$ at lower $\mathrm{w} / \mathrm{c}$ ratios but the effect $1 \mathrm{~s}$ small.

The effect of a wide range of cross-head speeds, $\dot{x}$, and thus of maximum flexural strain rates, $\varepsilon_{\max }$, on the toughness of $75-100$ day old paste

measured using the SENB test is shown in Fig. 1. The maximum flexural strain rate was determined from the equation of Terwilliger, Bowen and Gordon (1970)

$$
\dot{\varepsilon}_{\max }=\left(6 \mathrm{~d} / 1^{2}\right) \dot{\mathrm{x}}
$$

where $l$ is the beam span and $d$ the beam depth. The $K_{\text {IC }}$ values increase to maximum at a cross-head speed of about $5 \times 10^{-5} \mathrm{~m} \mathrm{~s}^{-1}$ and then sharply decrease. A similar strain rate dependence for $\mathrm{K}_{\mathrm{IC}}$ has been reported for alumina at high temperatures by Kromp and Pabst (1980). An increase in toughness with increasing cross-head speed in the lower range of speeds was reported by Higgins and Bailey (1976).

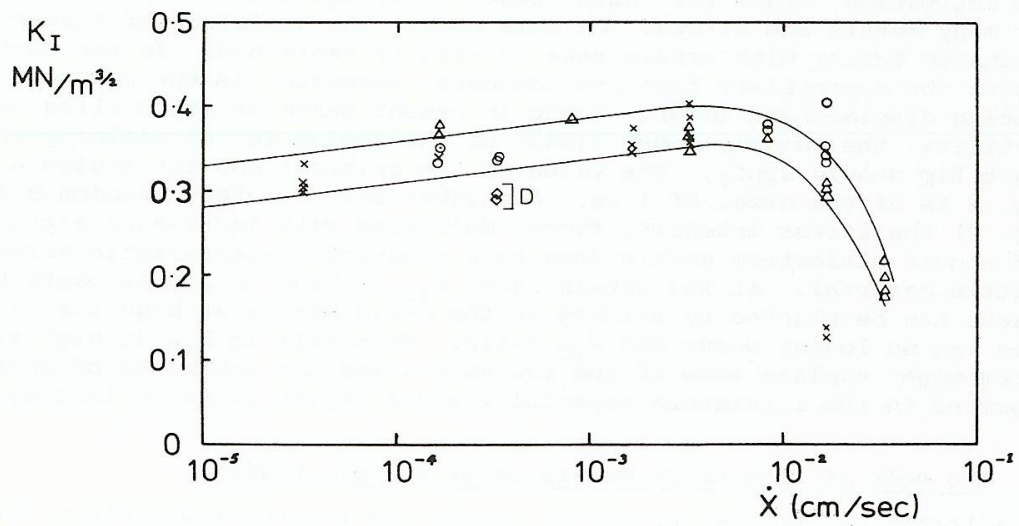

FIG. 1. Variation of $\mathrm{K}_{\mathrm{IC}}$ with cross head speed $\dot{\mathrm{X}}$ $x=75-85$ days old, $0=90$ days old, $\Delta=100$ days old, \rangle$=100$ days old and dried for $5-10 \mathrm{~min}$.
To test the effect of drying on fracture toughness, two SENB specimens were taken out of water and allowed to dry at room temperature for 5 and 10 minutes respectively. The specimen surfaces looked almost completely dry but the stress intensity factor of these specimens was reduced only by $15 \%$ (Fig. 1). Although this confirms the view that specimens should be kept wet during testing, the effect of short times of drying at least on 75-100 day old pastes appears to have been exaggerated by Higgins and Bailey (1976).

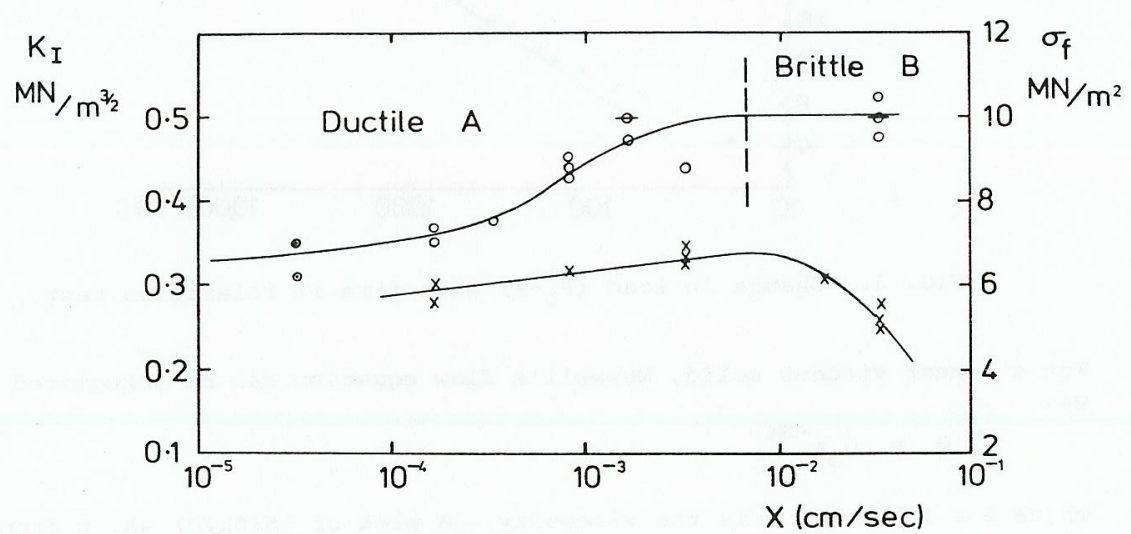

FIG. 2. Variation of $\mathrm{K}_{\mathrm{IC}}$ and $\sigma_{\mathrm{f}}$ with cross head speed $\dot{X}$ for specimens aged $35-40$ days.

Figure 2 shows the SENB fracture toughness and the flexural strength of unnotched specimens for $35-40$ day old beams of $20 \times 40 \times 160 \mathrm{~mm}$ size. The effect of cross-head speed on the fracture toughness is similar to that shown in Fig. 1, while the flexural strength increases with cross-head speed arkedly at about $10^{-5} \mathrm{~m} \mathrm{~s}^{-1}$ and then levels off. An increase in the size of unnotched beams to $40 \times 40 \times 160 \mathrm{~mm}$ did not affect the flexural strength significantly. The fracture toughness of cement paste increases only ffect was 0.5 .

A typical result of the change in load obtained from the relaxation tests is thown in Fig. 3. Equation 5 is obeyed at long times and the activation the strain rate dependence of the flexural strength (Gibbs, 1969), as

$$
\mathrm{v}=\mathrm{kT} \partial \ln \dot{\varepsilon} / \partial \sigma_{f}
$$

At cross-head speeds below the sudden increase near $10^{-5} \mathrm{~m} \mathrm{~s}^{-1}$, this yields a value of $\sim 1.5 \times 10^{4} \AA^{3}$. Two bend specimens were allowed to dry in air at room temperatures for about 30 days and then broken in bending at different in in rates; these gave an activation volume of $3.7 \times 10^{4} \AA^{3}$, in good agreement with the values found by Klug and Wittmann (1974). 


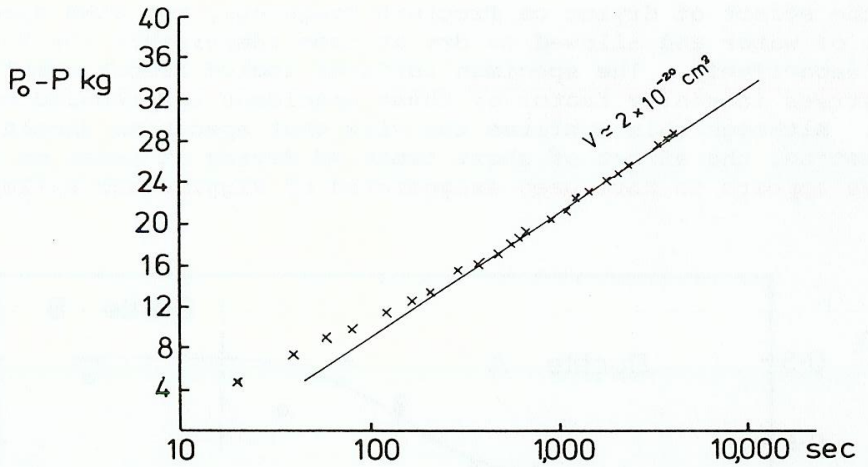

FIG. 3. Change in load $\left(\mathrm{P}_{\mathrm{O}}-\mathrm{P}\right)$ with time in relaxation test. For a linear viscous solid, Maxwell's flow equation can be integrated to
give

$$
\sigma=\sigma_{0} e^{-B t}
$$

where $B=1 / 3 n$, and $n$ is the viscosity. A plot of $\ln \left(\sigma_{\circ} / \sigma\right)$ vs. $t$ from the relaxation tests, Fig. 4, fails to give a straight line, suggesting that the flow of cement paste is non-linear. Equation 7 may be applied for cement paste only by replacing the term Bt by $\int_{0}^{t} \frac{d t}{3 n}$. A non-linear behaviour for cement paste is also suggested by the repeat relaxation tests, in which the magnitude of stress relaxation in the second relaxation cycle was smaller than that in the first cycle at corresponding times.

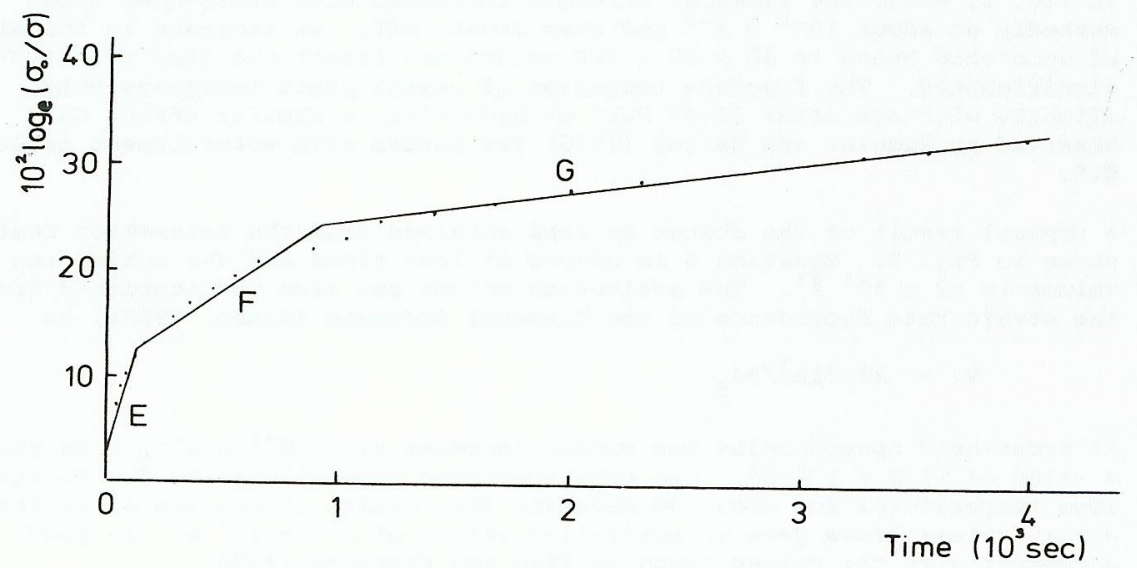

FIG. 4. Variation of load ratio $\sigma_{0} / \sigma$ during relaxation test.
DISCUSSION

1. The Ductile-Brittle Transition

The activation volumes measured at strain rates in the ductile region may be interpreted in terms of a thermally activated shear process, occurring between sheets of calcium silicate hydrate (C-S-H) gel. For displacements of the order of the Ca-Ca spacing found by Taylor (1979), these activation volumes correspond to the shear of sheets of gel of the size formed in the later stages of hydration. The presence of water molecules betwe would be sheets would ald the shear precimens. These activated shear processes were more dited during relaxation tests and during measurements of flexural observed at various strain rates. The possibility of a relaxation process strenth for that process. If the relaxation time is too large, the process cannot focur fast enough to maintain the externally imposed strain rate. Under these conditions another faster process must come into operation or brittle behaviour will intervene. In equation $7, \mathrm{~B}$ is equal to the relaxation frequency (i,e, the inverse of the relaxation time). From Fig. 4 and equation 7 , the relaxation frequency for the fastest relaxation process found in cement paste (region $\mathrm{E}$ in $\mathrm{Fig} .4$ ) is $10^{-3} \mathrm{~s}^{-1}$ which corresponds very well with the strain rate above which brittle behaviour is observed in Fig. 2. This suggests that the distinction between the ductile and the brittle regions does have physical significance.

2. The Effect of Strain Rate on Toughness

So far we have considered the relaxation process responsible for the ductile

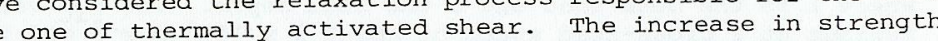
with strain rate in region $A$ is similar to that observed for ductile metallic materials, while the constant strength at high strain rates in region $B$ is characteristic of brittle materials. Such a transition from ductile to brittle behaviour with increased strain rate has been reported by Maddin and Masumoto (1972) for a micro-crystalline Pd-Si alloy. Furthermore, the activation volume for cement paste is of the variation of stress for many metals and alloys. On this basis, the variation of stress intensity factor with strain rate is readiy explained. In the ductile region the appropriate fracture toughness parameter is the critical crack opening displacement (COD). Since in cement paste we are dealing with micr ductility, the Dugdale model (1960) of the rglon in the vicinity of the crack tip should apply. The value of the critical cod for region A ig. 2 is of the order of 1 m. ig. 2) the stress lntic value for a and should ultinately set cement paste because brittle material. At cracks this can no longer occur and $\mathrm{K}_{\mathrm{IC}}$ falls. reported in the literature especially under impact rates of loading.

\section{The Role of Slow Crack Growth Under Dynamic Loading}

An alternative explanation of the relaxation process responsible for the An alternative is the formation and growth of stable micro-cracks. Evan (1974) has shown how the parameters of sub-critical crack growth can be determined from the strain-rate dependence of the flexural strength for dotot of $\log \sigma$ vs. $\log \dot{\varepsilon}$ should have 
slope $1 / 1+n$, where $n$ is the slope of the $\log v-\log K_{I}$ plot, determining slow crack growth. Plotted in this way, our flexural strengths from Fig. 2 reveal all of the features of slow crack growth at low strain rates, reverting to fully brittle behaviour at strain rates above $10^{-3} \mathrm{sec}^{-1}$. From our limited results the value of $\mathrm{n}$ for cement paste lies between 20 and 40 this extreme range includes the results of Nadeau, Mindess and Hay (1974) and Mindess and Nadeau (1977) of $\cong 35$ and 34.2, obtained directly from their $\log \mathrm{V}-\log \mathrm{K}$ measurements for cement pastes. Mindess and Nadeau's figure of 17.7 derived from the strain rate dependence of their flexural tests appears to arise from a rather particular interpretation of their data. A with their linterpretation suggests a figure of $w 40$, in closer agreement with their airect measurement of n. The relationship between micro-cracking (n)

ACKNOWLEDGEMENTS

The authors are grateful to the Marine Technology Directorate of SERC for financial support for this work.

REFERENCES

Brown, J. H. and Pomeroy, C. D. (1973) . Cem. \& Concr. Res., 3, 475

Brown, W. F. and Srawley, J. E. (1960) $\frac{\text { ASTM }, \frac{410}{8}, 13}{13}$.
Dugdale, D. S. (1960). J. Mech. Phys. Solids, 100.

Evans, A. G. (1974). J. Fract. Mech., 10, 251 .

Gibbs; G. B. (1969). Phil. Mag., 20, 867 .

Higgins, D. D. and Bailey, J. E. (1976). J. Mater. Sci., 11, 1995.

Hillemeier, B. and Hilsdorf, H. K. (1977). Cem. \& Concr. Res. . 7, 523.

Klug, P. and Wittmann, F. (1974). Mat. Sci. Eng., 15, 63 .

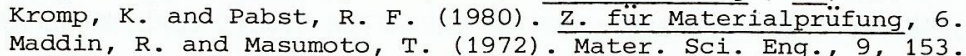

Mindess, S., Lawrence, F. W. and Kesler, C. E. (1977) . Cem. \& Concr. Res..

7. 31 .

Mindess, S. and Nadeau, J. S. (1977). Ceramic Bulletin, 56-4, 429.

Nadeau, J. S., Mindess, S. and Hay, J. M. (1974). J.Am. Ceram. Soc., 57, 51

Taylor, H. F. W. (1979). In J. Skalny (Ed.), Cement Production and Use.

Eng. Foundation, p.107.

Terwilliger, G. R., Bowen, H. K. and Gordon, R. S. (1970). J. Am. Ceram. Soc. , 53, 241 .

Williams, D. P. and Evans, A. G. (1973). J. Testing and Evaluation, 1, 264.

wittmann, F. (1974). In Bestimmung physikalischer Eigenschaften des

Zementsteins. Schriftenreihe Deutscher Aussehuss für Stahlbetan Heft, 323 Ziegeldorf, Z., Müller, H. S. and Hilsdorf, H. K. (1981). Advances in
Fracture Research, Vol. 5, 5th Int. Conf. on Fracture, Cannes. 